\title{
Hubungan Dukungan Suami Terhadap Pelaksanaan Inisiasi Menyusu Dini (IMD) Di Rumah Sakit
}

\author{
Rais Sholeh ${ }^{1,2}$, Agrina $^{1}$, Safri $^{1}$ \\ ${ }^{1}$ Departemen Ilmu Keperawatan, Fakultas Ilmu Keperawatan Universitas Riau, Pekanbaru, Indonesia \\ ${ }^{2}$ Rumah Sakit Syafira Pekanbaru, Riau, Indonesia \\ raissholeh@gmail.com
}

\begin{abstract}
Early breastfeeding initiation was the began of early breastfeeding with the mother at least one hour after birth. This research aims to determine correlation between husband's support for the implementation of early breastfeeding. The research method used is quantitative by using a research design that is descriptive correlation with cross sectional approach. Sampling method using accidental sampling technique with total sample 30 respondents. This research used questionnaires and observation sheet as measuring instrument. The inclusion criteria in this studied were normal birth mothers without any indication and complications such as Pre Eclampsia Severe and Hemoraghic Post Partum, normal-born infants who did not experience Low Birth Weight and Asphyxia, and mothers was accompanied by the husband during labor.Research results will of analyzed using alternative test Fisher Exact. The results showed significant correlatied between husband's supported for implementation of early breastfeeding ( $p$ value 0,030). Healthcare workers can be still develop related to IMD in post partum with the of husband's supported so that implementation of IMD for children can be perfect.
\end{abstract}

Keywords: Early Breastfeeding, Husband Support.

\begin{abstract}
Abstrak
Inisiasi menyusu dini (IMD) merupakan permulaan menyusu dini sekurang-kurangnya satu jam setelah lahir. Penelitian ini bertujuan untuk mengetahui hubungan antara dukungan suami terhadap pelaksanaan iniasi menyusu dini (IMD). Metode penelitian yang digunakan bersifat kuantatif dengan menggunakan desain penelitian yaitu deskriptif korelasi dengan pendekatan cross sectional. Metode pengambilan sampel menggunakan teknik accidental sampling dengan jumlah sampel 30 orang responden. Penelitian ini menggunakan kuesioner dan lembar observasi sebagai alat ukur. Kriteria inklusi pada penelitian ini adalah ibu yang melahirka secara normal tanpa ada indikasi dan komplikasi seperti Pre Eklampsia Berat (PEB) dan Hemoraghic Post Partum (HPP), bayi yang lahir normal yang tidak mengalami Berat Bayi Lahir Rendah (BBLR) dan Asfiksia, dan ibu yang di dampingi oleh suami saat persalinan. Hasil penelitian dianalisa menggunakan dengan uji alternatif Fisher exact. Hasil penelitian menunjukkan ada hubungan yang signifikan antara dukungan suami terhadap pelaksanaan inisiasi menyusu dini ( $p$ value 0,030 ). Pelayanan kesehatan dapat lebih mengembangkan terkait IMD pada ibu post partum dengan keterlibatan dukungan suami agar pelaksanaan IMD dapat diberikan sepenuhnya.
\end{abstract}

Kata kunci: Dukungan Suami, Inisiasi Menyusu Dini (IMD). 


\section{PENDAHULUAN}

Permasalahan yang belum tuntas ditangani saat ini salah satunya adalah permasalahan Angka Kematian Bayi (AKB), yang belum sesuai dengan target pencapaian Sustainable Development Goals (SDGs). Pemerintah terus berupaya untuk menurunkan jumlah angka kematian neonatus, yaitu dengan program Inisiasi Menyusu Dini (IMD) yang secara langsung akan berdampak positif terhadap pemberian ASI secara Ekslusif 0-6 bulan dengan menjamin semua bayi baru lahir mendapat IMD (Kementerian Kesehatan Republik Indonesia [Kemenkes RI], 2018).

IMD merupakan salah satu program World Health Organization (WHO) pada tahun 2007, dimana pada prinsipnya bayi harus aktif mencari puting susu ibu serta melakukan kontak kulit dengan ibu sekurang-kurangnya satu jam setelah lahir (Kemenkes RI, 2016). WHO juga mengatakan bahwa bayi yang menyusui secara dini dapat memberikan nutrisi terbaik yang perlukan oleh bayi sehingga pertumbuhan bayi menjadi optimal. Di samping itu, keberhasilan Inisiasi Menyusui Dini (IMD) mempengaruhi keberlangsungan pemberian ASI eksklusif dan durasi menyusui. Dengan demikian, kebutuhan nutrisi bayi akan terpenuhi hingga usia 2 tahun (Khasanah, 2011)

Anak di bawah umur 2 tahun di Indonesia telah mendapat ASI Sebanyak $96 \%$, namun hanya $50 \%$ yang mendapat ASI dalam satu jam pertama setelah lahir dan hanya $66 \%$ yang mendapat ASI dalam hari pertama setelah lahir. Sedangkan Prevalensi IMD di Indonesia sendiri masih lebih rendah yaitu 42,7\% (Kemenkes RI, 2016). Angka tersebut masih jauh tertinggal bila dibandingkan dengan negara-negara berkembang lain seperti Oman (85\%), Sri Lanka (75\%), dan
Filipina (54\%) (Statistic Indonesia and Macro International, 2008). Hal ini menunjukkan program IMD di Indonesia belum terlaksana secara optimal (Kemenkes RI, 2013)

Keberhasilan saat melewati proses IMD dalam satu jam pertama setelah kelahiran dapat mengurangi angka kematian bayi. Berdasarkan hasil penelitian Edmond (2006) bahwa didapatkan untuk ibu yang apabila dapat melakukan IMD pada satu jam pertama setelah bayi dilahirkan didapatkan hasil $22 \%$ nyawa bayi dibawah umur 28 hari dapat diselamatkan dan apabila IMD dilakukan diatas 2 jam setelah bayi dilahirkan sebesar $16 \%$ nyawa bayi dibawah umur 28 hari dapat terselamatkan. Dari hal ini dapat disimpulkan bahwa resiko kematian bayi dibawah umur 28 hari akan meningkat 6 kali lebih besar setiap kenaikan satu jamnya.

Bayi yang tidak diberikan IMD sesuai dengan yang dianjurkan akan berdampak pada semakin tingginya AKB di Indonesia dan juga berdampak kepada keberhasilan ASI Eksklusif 0-6 bulan dimana cakupan ASI eklusif berdasarkan riset sebelumnya maih jauh dari target (Agrina, 2015). ASI eksklusif sangat penting bagi bayi dari 0-6 bulan karena ASI eksklusif dapat memenuhi kebutuhan nutrisi gizi bayi serta melindungi bayi dari berbagai penyakit seperti diare dan infeksi saluran pernafasan akut (Kemenkes RI, 2016). Menurut Roesli (2008), manfaat ASI bagi bayi yaitu sebagai nutrisi, meningkatkan daya tahan tubuh, meningkatkan kecerdasan, dan mempererat jalinan kasih sayang antara ibu dan bayi. Keberhasilan pelaksanaan IMD, terutama untuk menjaga agar reflek oksitosin lancar yang dapat mempengaruhi produksi ASI saat bayi baru lahir. 
Rendahnya penerapan IMD di Indonesia disebabkan beberapa alasan, sebagaimana yang dijelaskan oleh Indramukti (2013) bahwa ada beberapa faktor penghambat penerapan IMD salah satunya kurangnya dukungan yang diberikan oleh suami (Breastfeeding father). Breastfeeding father merupakan dukungan penuh seorang suami kepada istrinya agar dapat berhasil dalam proses menyusui. Peran suami dalam keberhasilan menyusui dini sangat besar karena dengan hadir dan memberi dukungan kepada ibu saat pelaksanaan IMD dapat memberikan rasa percaya diri ibu untuk melakukan IMD dan dukungan suami terhadap ibu yang melahirkan termasuk dalam 10 langkah tata laksana IMD. keberhasilan menyusui pada kelompok suami yang mengerti ASI adalah 98,1\% (Roesli, 2012).

Dukungan merupakan sikap yang diberikan oleh keluarga yang membuat anggota keluarga mampu berfungsi dengan berbagai kepandaian dan akal seperti dengan memberikan perhatian, kasih sayang, serta empati (Friedman, Bowden, \& Jones, 2010). Dukungan suami adalah dukungan yang paling berarti bagi ibu. Ayah dapat berperan aktif dalam keberhasilan pelaksanaan IMD. Suami dapat memberikan dukungan secara emosional dan berperan aktif dengan memberikan bantuan-bantuan yang praktis. Hasil penelitian oleh Chalifiyah (2015) menunjukkan bahwa hampir sebagian responden suami mempunyai peran positif dalam medukung pelaksanaan IMD (66.7\%) dari 18 responden yang diteliti.

Pengalaman ibu yang menjalani IMD mengungkapkan bahwa faktor yang mendukung terlaksananya IMD adalah ibu mendapat dukungan baik dari tenaga kesehatan maupun keluarga terutama dukungan dari suami, serta adanya kebijakan pemerintah terkait pelaksanaan
IMD. Dukungan dibutuhkan disebabkan masih adanya persepsi ibu yang salah tentang pelaksaaan IMD setelah selesai melahirkan seperti ibu merasa ASI nya belum ada, ibu menganggap bahwa bayinya baru akan disusui jika dirinya dan bayinya sudah dalam keadaan bersih (mandi), serta ibu merasa kelelahan setelah proses persalinan dan baru mau menyusui bila keadaannya benar-benar pulih. Oleh sebab itu dengan adanya dukungan dari lingkungan sekitar terutama suami maka akan memudahkan pelaksanaan IMD berjalan dengan baik.

Lebih lanjut, penelitian Suryani dan Mularsih (2011) yang dilakukan kepada 30 suami yang istrinya paska melahirkan didapatkan hasil bahwa $60 \%$ suami mendukung IMD. Uji statistik menunjukkan bahwa ada hubungan yang signifikan antara dukungan suami dengan pelaksanaan IMD pada penelitian ini. Penelitian Sirajuddin, Abdullah dan Lumuya (2013) juga menunjukkan adanya hubungan dukungan suami terhadap pelaksanaan IMD dengan OR: 6,78. Hal ini memperlihatkan bahwa suami memiliki peran sangat penting, utamanya dalam hal mendukung ibu selama pelaksanaan IMD. Namun demikian, masih banyak ditemukan suami yang merasa bahwa pelaksanaan IMD menjadi tanggung jawab seorang ibu terhadap bayinya yang baru lahir sehingga suami tidak begitu mempedulikan perannya sebagai suami dalam keberhasilan pelaksanaan IMD (Roesli, 2008). Hal ini tentunya dapat mempengaruhi keberhasilan pelaksanaan IMD. Yang pada akhirnya juga dapat menghambat proses pemberian ASI secara eksklusif pada bayi 0-6 bulan.

Meskipun mayoritas hasil penelitian menunjukkan adanya hubungan dukungan suami dengan IMD namun penelitian Setiyorini (2015) malah menunjukkan hasil 
tidak adanya hubungan dukungan suami dengan pelaksanaan IMD di RS Panti Rapih Jogyakarta. Masih adanya perbedaan hasil penelitian tentang pengaruh dukungan suami terhadap pelaksanaan IMD ditambah belum adanya penelitian pelaksanaan IMD di RS Kota Pekanbaru dan dukungan suami, dimana angka keberhasilan IMD di Provinsi Riau masih di bawah angka IMD nasional (42,7\%), maka penelitian ini perlu dilakukan di kota Pekanbaru, Riau. Penelitian ini bertujuan ingin melihat bagaimana dukungan suami dengan pelaksanaan IMD di RS di kota Pekanbaru, Riau.

\section{METODE}

Jenis penelitian ini merupakan penelitian yang bersifat kuantitatif dengan desain penelitian deskriptif korelasi dengan pendekatan cross-sectional. Adapun variabel dalam penelitian ini yaitu dukungan suami sebagai variabel independen dan IMD sebagai variabel dependen. Penelitian ini dilakukan di Rumah Sakit yang dimulai dari bulan November 2018 sampai bulan Januari 2019.

Populasi dalam penelitian ini adalah suami yang mendampingi istrinya melahirkan. Teknik yang digunakan dalam pengambilan sampel adalah teknik accidental sampling sebanyak 30 orang responden dengan kriteria inklusi yaitu ibu yang bersedia menjadi responden penelitian, ibu yang melahirkan secara normal tanpa ada indikasi dan komplikasi seperti Pre Ekslampsi Berat (PEB) dan Hemorrhagic Post Partum (HPP), bayi yang lahir normal yang tidak mengalami Berat Bayi Lahir Rendah (BBLR) dan Asfiksia, dan ibu didampingi oleh suami saat persalinan.
Alat pengumpul data yang digunakan adalah kuesioner tentang dukungan suami yang terdiri dari 10 pernyataan dan lembar observasi tentang pelaksanaan IMD. Kuesioner yang digunakan pada penelitian adalah kuesioner yang dirancang oleh peneliti hasil modifikasi dari hasil penelitian Chalifiyah (2015) yang telah dilakukan uji validitas dan reliabilitas. Pada penelitian ini, peneliti menerapkan etika penelitian seperti seperti pemberian informed consent (lembar persetujuan menjadi responden, anonymity (tanpa nama) dan confidentiality (kerahasiaan).

Data dianalisis menggunakan uji alternatif Fisher exact dikarenakan tidak memenuhi syarat Uji statistik Chi-square dengan derajat kepercayaan $95 \%$ dan batas kemaknaan $\alpha 0,05$.

\section{HASIL}

Hasil penelitian pada tabel 1 menunjukkan bahwa mayoritas umur responden adalah dewasa tengah yaitu berusia 26-45 tahun sebanyak 90\%. Pada variabel pendidikan terakhir didapatkan bahwa mayoritas berada pada tingkat pendidikan SMA sebanyak 63,3\%, sedangkan status pekerjaan responden mayoritasnya adalah wiraswasta sebanyak $56,7 \%$, mayoritas kelompok agama responden adalah agama Islam sebanyak $80 \%$ dan ibu yang bersalin terbanyak yaitu multipara berjumlah $66,7 \%$. 
Tabel 1. Distribusi Frekuensi Karakteristik Responden

\begin{tabular}{|c|c|c|}
\hline Karakteristik Responden & $\frac{\text { Frekuensi }}{\mathrm{F}}$ & $\frac{\text { Presentase }}{(\%)}$ \\
\hline \multicolumn{3}{|l|}{ 1. Usia Suami } \\
\hline $\begin{array}{l}\text { Dewasa Awal } \\
(18-25 \text { tahun })\end{array}$ & 3 & 10,0 \\
\hline $\begin{array}{c}\text { Dewasa Tengah } \\
(26-35 \text { tahun })\end{array}$ & 27 & 90,0 \\
\hline \multicolumn{3}{|l|}{ 2. Pendidikan Terakhir } \\
\hline SMP & 1 & 3,3 \\
\hline SMA & 19 & 63,3 \\
\hline Perguruan Tinggi & 10 & 33,3 \\
\hline \multicolumn{3}{|l|}{ 3. Pekerjaan } \\
\hline PNS & 6 & 20,0 \\
\hline Karyawan Swasta & 7 & 23,3 \\
\hline Wiraswasta & 17 & 56,7 \\
\hline \multicolumn{3}{|l|}{ 4. Agama } \\
\hline Islam & 24 & 80,0 \\
\hline Kristen & 5 & 16,7 \\
\hline Lainnya & 1 & 3,3 \\
\hline \multicolumn{3}{|l|}{ 5. Paritas Ibu } \\
\hline Primipara & 10 & 33,3 \\
\hline Multipara & 20 & 66,7 \\
\hline
\end{tabular}

2. Dukungan Suami dan Inisiasi

Menyusu Dini (IMD)

Tabel 2. Distribusi Frekuensi

Berdasarkan Dukungan Suami $(n=30)$

\begin{tabular}{lcc}
\hline Dukungan & Frekuensi & Persentase \\
\cline { 2 - 3 } \multicolumn{1}{c}{ suami } & F & \% \\
\hline Positif & 21 & 70,0 \\
Negatif & 9 & 30,0 \\
\hline
\end{tabular}

Tabel 2 menunjukkan bahwa dukungan suami responden terbanyak yaitu positif berjumlah 21 orang $(70 \%)$.

Tabel 3. Distribusi Frekuensi Berdasarkan Pelaksanaan Inisiasi Menyusu Dini (n=30)

\begin{tabular}{lcc}
\hline \multicolumn{1}{c}{ Pelaksanaan } & Frekuensi & Persentase \\
\cline { 2 - 3 } IMD & F & $\mathbf{\%}$ \\
\hline $\begin{array}{l}\text { Terlaksana } \\
\text { sepenuhnya }\end{array}$ & 21 & 70,0 \\
$\begin{array}{l}\text { Terlaksana } \\
\text { sebagian }\end{array}$ & 9 & 30,0 \\
\hline
\end{tabular}

Tabel 3 menunjukkan bahwa pelaksanaan IMD terlaksana sepenuhnya berjumlah $70 \%$.

Tabel 4. Hubungan dukungan suami terhadap pelaksanaan inisiasi menyusu $\operatorname{dini}(n=30)$

\begin{tabular}{lccccccc}
\hline \multirow{2}{*}{$\begin{array}{l}\text { Dukungan } \\
\text { Suami }\end{array}$} & $\begin{array}{c}\text { Terlaksana } \\
\text { sepenuhnya }\end{array}$ & \multicolumn{2}{c}{$\begin{array}{c}\text { Terlaksana } \\
\text { sebagian }\end{array}$} & \multicolumn{2}{c}{ Total } & \multirow{2}{*}{$\begin{array}{c}\boldsymbol{P} \\
\text { value }\end{array}$} \\
\hline Positif & $\mathbf{N}$ & $\mathbf{\%}$ & $\mathbf{N}$ & $\mathbf{\%}$ & $\mathbf{N}$ & $\boldsymbol{\%}$ & \\
Negatif & 4 & 85 & 3 & 15 & 20 & 100 & 0,030 \\
\cline { 1 - 7 } Total & 21 & 70 & 6 & 60 & 10 & 100 & \\
\hline
\end{tabular}

Tabel 4 memperlihatkan bahwa semakin positif dukungan suami maka pelaksanaan IMD akan terlaksana sepenuhnya. Uji statistik di dapatkan bahwa ada hubungan yang signifikan antara dukungan suami dengan pelaksanaan IMD ( $p$ value $<0,05)$.

\section{PEMBAHASAN}

\section{Karakteristik Responden}

Hasil penelitian yang telah dilakukan didapatkan bahwa mayoritas umur responden adalah dewasa tengah yaitu berusia 26-45 tahun, pada usia ini merupakan usia produktif yang sangat dianjurkan untuk melahirkan dan mempunyai anak. Semakin bertambah usia akan semakin berkembang pula daya tangkap dan pola pikir seseorang terhadap apa yang dialaminya, sehingga dapat meningkatkan pengetahuan yang lebih baik lagi dengan bertambahnya umur seseorang akan terjadi perubahan pada aspek fisik dan psikologis (mental) (Notoatmodjo, 2010). Semakin cukup umur, tingkat kematangan seseorang akan lebih matang dalam berfikir dan bekerja, pada usia dewasa muda, individu akan lebih berperan aktif dan 
bertanggung jawab dalam kegiatan sehari-hari seperti dalam mengasuh anak dan mengurus rumah tangganya (Nursalam, 2008).

Variabel pendidikan terakhir menunjukkan data bahwa mayoritas responden berada pada tingkat pendidikan SMA sebanyak 63,3\%, sedangkan mayoritas status pekerjaan responden adalah wiraswasta sebanyak $56,7 \%$. Sejalan dengan hasil penelitian yang dilakukan oleh Indramukti (2013) yang menunjukkan bahwa tidak ada hubungan antara tingkat pendidikan dengan praktik IMD pada ibu pasca bersalin normal di wilayah kerja Puskesmas Blado I Kabupaten Batang (p value $=1,000)$.

Notoatmodjo (2007) mengatakan bahwa suatu pekerjaan Seseorang mempengaruhi pada pengetahuan yang akan didapatkan, karena seseorang yang bekerja akan berinteraksi dengan orang lain sehingga akan mendapatkan lebih banyak informasi yang menambah pengetahuan serta hal ini juga akan menambah pengalaman seseorang.

Mayoritas kelompok agama responden adalah agama Islam yaitu sebanyak 24 orang (80\%), dimana agama Islam dalam Al-Qur'an sudah di jelaskan bahwa ASI di berikan kepada bayi sampai usia 2 tahun. Kepercayaan adalah komponen kognitif dari faktor sosio-psikologis, dimana keyakinan bahwa sesuatu itu benar atau salah yang akan diterapkan dalam kehidupan sehari-hari (Notoatmodjo, 2007). Sedangkan ibu yang bersalin terbanyak yaitu multipara berjumlah $66,7 \%$.

Prawirohardjo (2008) mengatakan bahwa berdasarkan paritas pada ibu didapatkan jika ibu yang jumlah paritas $>$ tiga kali maka ibu cenderung tidak akan berhasil untuk melakukan IMD dikarenakan dipengaruhi faktor emosional pada ibu yang sudah menghadapi kesulitan dalam persalinan/kehamilan. Pada ibu yang jumlah paritas 1-3 akan memiliki maturasi yang besar untuk dapat melakukan IMD pada bayinya. Aspek psikologis juga dapat mempengaruhi ibu dalam memberikan IMD pada anaknya.

\section{Dukungan suami dan pelaksanaan} IMD

Hasil penelitian ini menunjukkan bahwa semakin positif dukungan yang diberikan suami kepada ibu yang melaksanakan IMD maka pelaksanaan IMD akan terlaksana sepenuhnya. Hasil analisis menunjukkan bahwa ada hubungan yang signifikan antara dukungan suami terhadap pelaksanaan inisiasi menyusu dini dengan nilai $p$ value $=0,030$.

Hasil ini sesuai dengan penelitian Suryani dan Mularsih (2011) menyatakan bahwa dari hasil analisa diperoleh ada hubungan dukungan suami pada pelaksanaan inisiasi menyusu dini yang dilakukan ibu pada bayi setelah post partum di BPS Semarang. Dari 18 hanya 14 responden yang mendapatkan dukungan suami pada keberhasilan pelaksanaan IMD dengan persentase $77,8 \%$, sedangkan yang tidak mendapatkan dukungan suami, diperoleh hasil bahwa dari 12 responden hanya 9 responden yang tidak berhasil melaksanakan IMD 75\%.

Dukungan suami adalah salah satu bentuk interaksi yang di dalamnya terdapat hubungan yang saling memberi dan menerima bantuan yang bersifat nyata yang dilakukan oleh suami terhadap istrinya (Hidayat, 2005). 
Suami merupakan orang terdekat bagi ibu menyusui yang kehadirannya selalu di harapkan ada disisi ibu dan selalu siap memberi bantuan. Dukungan yang suami berikan secara terus menerus dapat mempengaruhi keberhasilan ibu dalam menyusui (Swasono, 2008).

Hasil penelitian lain oleh Chalifiyah (2015) tentang peran suami dalam mendukung pelakasanaan IMD di RSU Dr. Wahidin Sudiro Husodo Mojokerto didapatkan 18 responden hampir setengah responden mempunyai peran negatif dalam mendukung pelaksanaan IMD yaitu 33,3\% dan di dapatkan hampir sebagian responden mempunyai peran positif dalam mendukung pelaksanaan IMD yaitu $66,7 \%$.

Dukungan adalah suatu sikap yang diberikan oleh keluarga, yang membuat anggota keluarga mampu berfungsi dengan berbagai kepandaian dan akal, salah satu contohnya adalah memberikan perhatian, kasih sayang, serta empati yang diberikan oleh keluarga terutama oleh suami (Friedman, Bowden, \& Jones, 2010). Dukungan suami merupakan dukungan yang paling berarti bagi ibu. Ayah dapat berperan aktif dalam keberhasilan pelaksanaan IMD. Suami cukup memberikan dukungan secara emosional dan berperan aktif dengan memberikan bantuan-bantuan yang praktis seperti mempersiapkan kebutuhan ibu selama proses pelaksanaan IMD dan memberikan makan serta minum. Oleh karena itu, dukungan suami merupakan salah satu faktor yang mempengaruhi.

Hasil beberapa penelitian oleh Legawati dan Julia (2011) dan Indamukti (2013) yang telah dilakukan tentang hubungan antara proses persalinan dengan pelaksanaan IMD, didapatkan hasil bahwa keberhasilan IMD pada proses persalinan normal lebih baik dan berhasil dibandingkan pada persalinan sectio caesarea. Hasil penelitian tersebut berkaitan dengan penelitian di jepang bahwa salah satu faktor yang dapat mempengaruhi ibu untuk tidak bisa melakukan IMD adalah pada persalinan SC dan karena pengaruh pada anestesi saat ibu operasi dan setelah operasi belum keluarnya ASI.

Hasil penelitian menunjukkan penyebab masih kurang terlaksananya IMD secara penuh dikarenakan oleh masih banyak dari seorang suami yang berpendapat salah bahwa menyusui adalah urusan ibu dan bayinya. Sebagian besar para suami menganggap bahwa cukup menjadi pengamat yang pasif saja. Padahal sebenarnya suami mempunyai peran yang sangat berpengaruh dalam menentukan untuk keberhasilan ibu dalam menyusui. Suami yang memberikan perhatian kepada ibu pasca melahirkan maka dapat berpengaruh dalam kelancaran reflex pengeluaran ASI (let down reflex) yang sangat dipengaruhi juga oleh keadaan emosi atau perasaan ibu. Keterlibatan suami dalam proses IMD akan memberikan motivasi untuk ibu dalam menyusui anaknya, jika ibu sudah memiliki dukungan dan motivasi dari suami dalam proses pelaksaan IMD dan menyusui anaknya secara otomatis ibu akan optimis dan termotivasi untuk mengeluarkan banyak ASI pada bayinya. Dukungan suami adalah dukungan yang paling berarti bagi ibu (Roesli, 2008). 


\section{KESIMPULAN DAN SARAN}

Mayoritas responden berada pada usia dewasa tengah (26-45 tahun) dengan pendidikan terakhir terbanyak adalah menengah ke atas, riwayat persalinan istri yaitu multipara. Hasil uji statistik menunjukkan bahwa ada hubungan yang signifikan dukungan suami yang memberikan dukungan positif kepada istri akan langsung melaksanakan IMD secara keseluruhan dibandingkan suami yang tidak memberikan dukungan dengan hasil $p$ value $0,030<\alpha(0,05)$, sehingga didapatkan dukungan suami terhadap pelaksanaan inisiasi menyusu dini akan terlaksana sepenuhnya.

Penting bagi Rumah sakit untuk dapat mensupport pelaksanaan terkait Inisiasi Menyusu Dini (IMD) pada ibu post partum dengan melibatkan dukungan suami agar pelaksanaan IMD dapat terlaksana sebelumnya.

\section{DAFTAR PUSTAKA}

Agrina, Kimura, R., Tsuda, A. Mother's exclusive breastfeeding behavior: A cross sectional study in Pekanbaru, Indonesia. (2015). International Journal of Research in Medical Sciences, 3 (1) , 109-118.

Chalifiyah, I. (2015). Peran suami dalam mendukung pelaksanaan inisiasi menyusu dini (IMD) di RSU Dr. Wahidin Sudiro Husodo Mojokerto.

Edmond K. M., Zandoh, C., Quigley, M. A., Amenga-Etego, S., Owusu-Agyei, S., Kirkwood, B. R. (2006). Delayed breastfeeding initiation increases risk of neonatal mortality. Pediatrics, 117(3), 380-386.
Friedman, M. M., Bowden, O., \& Jones, M. (2010). Buku ajar keperawatan keluarga. Jakarta: EGC.

Hidayat, A. A. (2005). Pengantar ilmu keperawatan anak 1. Jakarta: Salemba Medika.

Indramukti, F. (2013). Faktor yang berhubungan dengan praktik inisiasi menyusu dini (IMD) pada Ibu Pasca Bersalin Normal. Unnes Journal of Public Health, 2(2), 1-8. doi: 10.15294/ujph.v2i2.2991

Kementerian Kesehatan Republik Indonesia. (2013). Survei demografi dan kesehatan Indonesia 2012. Diperoleh dari http://kesga.kemkes.go.id/images/pedo man/SDKI\%202012-Indonesia.pdf

Kemenkes RI. (2016). Profil kesehatan Indonesia tahun 2016. Diperoleh dari http://www.depkes.go.id/resources/do wnload/pusdatin/profil-kesehatanindonesia/profil-kesehatan-Indonesia2015.pdf.

Kementerian Kesehatan Republik Indonesia. (2018). Rapat kerja kesehatan nasional Tahun 2018. Diperoleh dari http://www.depkes.go.id/resources/do wnload/info-terkini/materi pra rakerkesnas 2018/Rangkuman Rakerkesnas 2018.pdf.

Khasanah, N. (2011). ASI atau susu formula ya dan panduan lengkap seputar ASI dan susu formula. Jogjakarta: Nuha Medika.

Legawati, Dasuki, D., \& Julia, M. (2011). Pengaruh inisisasi menyusu dini terhadap praktik menyusui 1 bulan 
pertama. Jurnal Gizi Klinik Indonesia, 8(2), 60-68.

Notoatmodjo, S. (2010). Ilmu perilaku kesehatan. Jakarta: Rineka Cipta.

Nursalam. (2008). Konsep \& penerapan metodologi penelitian ilmu keperawatan. Jakarta: Salemba Medika.

Prawirohardjo, S. (2008). Ilmu kebidanan. Jakarta: Bina Pustaka Sarwono.

Roesli, U. (2008). Inisiasi menyusu dini plus ASI eksklusif. Jakarta: Pustaka Bunda.

Roesli, U. (2012). Panduan inisiasi menyusu dini plus ASI eksklusif. Jakarta: Pustaka Bunda.

Sirajuddin, S., Abdullah, T., \& Lumula, S. N. (2013). Determinan pelaksanaan inisiasi menyusu dini. Jurnal Kesehatan Masyarakat Nasional, 8 (3), 99-103. doi: 10.21109/kesmas.v8i3.350

Setiyorini, A. (2015). Faktor-faktor pengaruh keberhasilan pelaksanaan inisiasi menyusu dini (IMD) di Rumah Sakit Panti Rapih Yogyakarta. Diperoleh dari http://ejournal.stikesborromeus.ac.id/fi le/8-7.pdf

Suryani, N. D., \& Mularsih, S. (2011). Hubungan dukungan suami dengan pelaksanaan inisiasi menyusui dini pada ibu post-partum di BPS Kota Semarang. Dinamika Kebidanan, 1(1).

Swasono. (2008). Ayah perlu dukung ibu menyusui. Jakarta: Aqwame 